Editorial

\title{
EXERCISE YOUR WRITE
}

\section{Arunachalam Kumar, Editor, NUJHS, Mangalore - 575 018, India}

Well begun, it is said, is half done! When our nascent Nitte University embarked on its ambitious project to launch a research journal it was taking up a challenge few dare to take on. Bringing out a quality publication replete with scholarly submissions, regularly and on time is no cakewalk. The time, energy and funding required for the undertaking apart, the onus to maintain a high standard for acceptance and publication of articles, makes our brief, doubly crippling.

However, I am delighted to add that the Nitte Journal of Health Science has now been granted the ISSN and has already found inclusion in the journals master-list of the international reference data base, the Index Copernicus, Poland. The NUJHS hopes to reach out to more through listing in other prestigious reference bases and citation indexes in the next few years. The only way forwards is strictly promote publication of hi-standard original research initiatives and further the cause of innovative interventions. I am elated to note that this issue carries contributions from nursing, dental, pharmacy and medical faculties proving that there is space and scope for a whole gamut of health sciences that need to explored and researched on and a vehicle such as NUJHSis being judiciously explored by professionals from every sector in the health care delivery system.

Fodder and raw material for conjuring up path-breaking innovations and inventiveness are aplenty. All it requires to convert observations to research is application of mind and an expending of time. The rewards an author reaps for publishing a readable, education and informative article cannot be quantified in numbers or size.

The pages of NUJHS are opens to any aspiring author or budding researcher: the editorial board specially encourages young professionals to explore the opportunities plentifully available in the world of research: to emphasize this 'encourage the young' author policy of ours, I invite your attention to an original article in this issue, authored by interns.

Share your observations, notes and inputs with those who matter - put it in writing and get them in print

\footnotetext{
The Nitte University Journal of Health Science (NUJHS) is a peer-reviewed indexed quarterly research publication. The annual subscription for NUJHS is Rs 1,000/- (4 issues). DDs / Checks payable to Nitte University J ournal of Health Sciences, Syndicate Bank, ABSM IDS Branch, Deralakatte can be mailed to Dr. Arunachalam Kumar, Editor, NUJHS Journal Office, K. S. Hegde M edical Academy, M angalore 585018, India. Single copies are available on payment of Rs. 300 each, by cash or check at the Journal Office. For 'Instructions to authors' refer to the inaugural issue (NUJHS, Vol.1: No. 1-3 SEP 2011) and also on the Nitte University webpage linkhttp://nitte.edu.in/journal/
} 